Methods Cross-sectional data from The Irish Longitudinal Study on Ageing (TILDA), a population-based study of 8175 people aged $\geq 50$ years was analysed. Those in employment were grouped according to the occupational social classification, an internationally recognised categorisation widely used to analyse social and health variations. Statistical analyses were performed using SPSS (V22.0, SPSS Inc, IL). Tests for main effects were conducted using an ordinal logistic regression using a generalised linear model. The relationship between self-rated health and social class was examined with age, gender, educational status, medical history and multiple lifestyle factors (body mass index (BMI), smoking, alcohol consumption, physical activity) as the independent variables.

Results 30\% (2440/8175) of the TILDA cohort were in employment at the time of the study and therefore included in the analysis. There was a statistically significant association between selfrated health and occupational social class after adjusting for independent variables as described above (p-value 0.014).

Conclusion There is a strong cross-sectional association between self-rated health and occupational social class in those at work over 50 years of age in Ireland. This association is preserved after adjusting for gender, age, past medical history, lifestyle behaviours and educational status. Further research is required to establish if this association persists among retirees. This study confirms the need to tailor health promotion and well-being programs to the different occupational social groups to maximise potential health benefits and to preserve employment among older workers

\section{ATTITUDES TOWARD WORKING CONDITIONS: ARE EUROPEAN UNION WORKERS SATISFIED WITH THEIR WORKING HOURS AND WORK-LIFE BALANCE?}

${ }^{1}$ Nuria Matilla-Santander* ${ }^{1}$ Cristina Lidón-Moyano, ${ }^{1}$ Adrián González-Madon, ${ }^{1}$ Kailey Bunch, 'Juan Carlos Martín-Sánchez, 1,2Jose M Martínez-Sánchez. 'Group of Evaluation of Health Determinants and Health Policies, Sant Cugat del Valless, Spain; ${ }^{2}$ Tobacco Control Unit, Hospitalet de Llobregat, Spain

\subsection{6/oemed-2018-ICOHabstracts. 110}

Introduction Neoliberal economic globalisation has changed the definition of standard employment and this could be affecting work-life balance. The objective of this study is to describe the satisfaction with working hours and satisfaction with work-life balance and their association in the European Union (EU-28).

Methods This is a cross-sectional study based on data from the Flash Eurobarometer 398 among workers of the EU-28 from $2014(n=13,683)$. We calculated percentages and their $95 \%$ confidence intervals $(95 \% \mathrm{CI})$. We also fit a multi-level generalised linear model (GLM) using the Poisson family, in order to calculate the adjusted prevalence ratios (aPR) of satisfaction with work-life balance based on working hours. All analyses were stratified for individual, employment and welfare regime country classification.

Results Satisfaction with working hours and work-life balance was $80.62 \%$ and $74.48 \%$, respectively, and was significantly higher among women. The highest percentages of satisfaction were found in Nordic welfare regime countries $(90.2 \%$ and $85.3 \%$, respectively). There was a statistically significant association between satisfaction with working hours and work-life balance $(\mathrm{aPR}=2.63,95 \% \mathrm{CI}: 2.28$ to 3.04$)$, and the magnitude of the association differed by individual and employment characteristics and welfare regime country classification. The main reasons declared for dissatisfaction were 'excessive working hours' (48.7\%), 'shift work' (27.9\%), and 'inability to influence the work schedule' (28.3\%). Differences were observed according to sex and type of welfare regime.

Conclusion European Union workers are highly satisfied with their working hours and work-life balance, and there is a strong association between satisfaction with work-life balance and working hours. There are still differences between sexes and welfare regimes.The Nordic model of social policies should be considered to improve satisfaction with work-life balance in the rest of the EU-28.

\section{THE EFFECTS OF OCCUPATION ON THE EVOLUTION OF BMI IN A BELGIAN EMPLOYEE POPULATION}

${ }^{1}$ Martijn Schouteden*, 'Matthias Coene, ${ }^{1}$ Chris Verbeek, ${ }^{1}$ Marc Beurms, ${ }^{1,2}$ Lode Godderis. ${ }^{1}$ Idewe, External Service for Prevention and Protection at Work, Belgium; ${ }^{2}$ Katholieke Universiteit Leuven, Centre for Environment and Health, Belgium

\subsection{6/oemed-2018-ICOHabstracts. 111}

Introduction During medical investigation, occupational health physicians collect huge amounts of scattered data about their patients. Recently, these data have been integrated into a single data warehouse. In the current study, this data warehouse has been addressed to study the evolution of BMI, and investigate how this trend is effected by the occupation of the employee, controlled for gender and age.

Methods Around 78000 employees were followed-up from 1993 onwards, with following variables: BMI, age, sex, and isco encoded occupation. Multilevel analyses was performed to study the evolution of BMI, with time and time ${ }^{2}$ as time-varying variable, and sex, age at start of measurement and occupation as time-independent variables. Including time ${ }^{2}$ allows for modelling curvilinear trends over time. Random effects were allowed for the intercept and time-varying variables.

Result Over the 23 years of follow-up, we observed a high drop-out of around 90\%. Nontheless, all occupations were still represented at the last measurement. $52.8 \%$ was male, mean age was 34.34 years $(S D=9.43)$ at the start of the study. Analyses showed that BMI increases curvilinear with age: the younger, the steeper the curve; Males have higher BMI than females. Occupation also has an effect: Highest BMI was observed with Service personnel of machinery and installations assemblers; the increase of BMI was highest for Leading functions. Random effects showed large inter-individual differences in BMI at starting point and on effect of time. Discussion We've illustrated how the data warehous can be accessed to answer substantive research questions. Differences in evolution of BMI seems to be related to occupation. The strong curvilinear effect probably indicates healthy worker effect. The high dropout might be explained by employees changing companies, companies changing external service, and/ or the reach of retirement age.

\section{THE ASSOCIATION OF AGE AND CHRONOTYPE IN DAY AND ROTATING SHIFT WORKERS OF A LARGE GERMAN CHEMICAL COMPANY}

M Schuster*, M Claus, S Webendörfer, C Oberlinner. Corporate Health Management, BASF SE, Ludwigshafen, Germany

10.1136/oemed-2018-ICOHabstracts. 112 